\title{
Role of Social Embeddedness Approach in Perceived Organizational Support
}

\author{
Global Journal of Social Sciences \\ Studies \\ Vol. 7, No. 1, 1-11,2021 \\ e-ISSN: 2518-061

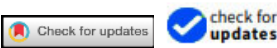

\author{
Fen-ling Chen \\ Jim Woodley \\ Chaoyang University of Technology, Taiwan. \\ ${ }^{2}$ University of North Dakota, United States of America. \\ (20) Corresponding Author
}

\section{ABSTRACT}

The main aim of this research paper was to determine the role of social embeddedness approach in perceived organizational support with respect to Vietnamn manufacturing companies. This research paper has adopted primary research data collected using close-ended survey questionnaire. The scale is taken to be 5-point ranging from strongly agree to strongly disagree. The sample size of the study is 400 employees belonging from Vietnamn Manufacturing Companies. The data has been analysed using SEM approach which includes path analysis and Confirmatory Factor Analysis (CFA) using SmartPLS. The results of this paper has revealed that out of the three independent variables tested, only network quality and size had significant relationship with perceived organismal support at 0.000 and 0.013 respectively. Network density has no significant impact on perceived organismal support.

Keywords: Social embeddedness, Perceived organizational support, Network size, Network quality, Network density.

DOI: $10.20448 / 807.7 .1 .1 .11$

Citation | Fen-ling Chen; Jim Woodley (2021). Role of Social Embeddedness Approach in Perceived Organizational Support. Global Journal of Social Sciences Studies, 7(1): 1-11.

Copyright: This work is licensed under a Creative Commons Attribution 3.0 License

Funding: This study received no specific financial support.

Competing Interests: The authors declare that they have no competing interests.

History: 5 January 2021/ Revised: 8 March 2021/ Accepted: 13 April 2021/ Published: 25 May 2021

Publisher: Online Science Publishing 


\section{Highlights of this paper}

- The study determines the role of social embeddedness approach in perceived organizational support with respect to Vietnamn manufacturing companies.

- This study has adopted primary research data collected using close-ended survey questionnaire.

- The network density has no significant impact on perceived organismal support.

\section{INTRODUCTION}

The popularity of social media networks amongst the public has compelled the organisations to remain connected, therefore, the employees and other individuals engage in recursive and stable social exchanges (Allen \& Shanock, 2012). The mentioned phenomenon is regarded as social embeddedness. In the context of organisations, the exchanges are generally socio-emotional and instrumental between the colleagues. The study carried out by Hayton, Carnabuci, and Eisenberger (2011) asserted that the approaches adopted by the organisations to enhance social embeddedness an engagement help the employees to perceive the organisational support positively. The study conducted by Kanamaru (2015) implied that the concept of social embeddedness in entrepreneurship and businesses is evolving. Concerning this aspect, the following study aims to evaluate the role of social embeddedness approach used in the Vietnam manufacturing companies in developing the perception regarding organisational support of the employees.

According to the study conducted by Trading Economics (2020) it was found that the manufacturing industry of Vietnam is expected to further increase by $11 \%$ because of their growing industries and use of technology. The manufacturing production in Vietnam was at averaged $10.36 \%$ from the year 2011 to 2020. Out of the many industries that are established in Vietnam, textile industry is most growing industry. Textile clothing has become one of the largest exporting products. The trade relation of Vietnam with other countries is also very favourable as the country is engaged in exporting their high quality fabrics and products to other countries. After China, Vietnam has successfully become one of the top exporters of footwear and clothing products to USA. Apart from textile industry, the electronics industry is also increasing at a higher pace where computers, phones and other parts are manufactured at lost costs and exported too. The low costs of wages in Vietnam are also beneficial in terms of attracting investors to establish their industries. Apart from these two industries, food processing, automobile and petrochemicals are also huge industries that play a vital role in growing the Vietnam economy.

\section{LITERATURE REVIEW}

\subsection{Theoretical Framework}

The previous researches indicate that social relationship at workplace play a major role in the development and productivity of employees. Social exchange at work includes different aspects including social networks and exchange of supportive resources. Podolny and Baron (1997) have mentioned in their work that embedded relationship at work are found to be more robust and have a long terms nature as compared with the sporadic exchanges. Social support helps the employees to complete their tasks and to achieve their goals effectively by relying upon the resources that are provided to them by their social network at the workplace (Akgunduz \& Sanli, 2017). The resources can vary from advice, information, equipment, feedback, supplies, approval, emotional support, praise, and social identity needs. The resources can be divided into instruments resources and expressive exchanges. Both the kinds of resources tend to promote one another. The instrumental exchanges motivate the development of trust, responsiveness to socio-emotional needs, and development of social interaction. Likewise, expressive exchange increases the probability of offering and requesting (Chen \& Shaffer, 2017). 
In the light of the above discussion related to both the instrumental exchange and expressive exchange at workplace allow the employees to work efficiently and achieve their goals. According to Duffy, Ganster, and Pagon (2002) socially embedded exchange tend to create a favourable work environment. Wu and $\mathrm{Hu}(2009)$ in this regard have stated through their research that the well-being and effectiveness of an employee can be impacted positively with the help of social relationships at work. This research paper contend that social embeddedness approach in an organisation can contribute positively towards perceived organisational support (POS). This is because the employees tend to identify their network with the organisation because the organisation is responsible for building the culture at the workplace (Tabak \& Hendy, 2016). Thus, the support of the network is dependent on the organisation. It can be inferred that the support received by employees through their network leads to greater POS. Networks in organisation help the employees to feel that they are the accepted members of the organisation, resulting in triggering the feeling of belongingness. Consequently, as per the findings of Allen., Shore, and Griffeth (2003) social acceptance contributes significantly and positively towards the POS. In order to best understand the impact of social embeddedness (expressive and instrumental excahnges) on the POS, it is important to take into consideration the factors of network such as size, quality, and density. These factors or characteristics are important to be considered because they tend to influence attitude, behaviour, and beliefs of individuals working in an organisation (Mehra, Kilduff, \& Brass, 2001). Also, taking into consideration the above mentioned factors also helps in developing the discussion and not only focusing over the general perception of support by the employees. Size, density, and quality of network is important because it tends to impact the value and amount of resources exchanged within an organisation. The following section includes a discussion of each characteristics and its impact on the POS.

The size of the network is defined as the number of people or persons in an organisation that are directly related or connected with one person. The connections and relationship in a socially embedded network have several characteristics such as: long-term, reciprocated, strong, existence of mutual support, and multiplex (Fan, Xia, Zhang, \& Chen, 2019). Hence, as per the findings of Lin (2017), the large size of a network can be attributed to higher content of support and socio-emotional connection of an employee with their network. Based on the above discussion, following is the first hypothesis of this research paper:

\section{H1: Network size has a positive association with POS.}

The next network characteristic which is taken into consideration for this research is density of network. It regards to the extent with which the participants of a network are connected with one another. The more participants concerned or connected with one another, denser the social network is. Buskens and Raub (2002) have mentioned through their research that participants of dense networks tend to have a stronger incentive to engage in supportive behaviour as compared to the employees who belong to a sparse network. The benefits of engaging in supportive behaviour increase with the density of the network (Pollack, Rutherford, Seers, Coy, \& Hanson, 2016). Raub and Weesie (1990) have inferred through their findings that in denser networks, participants tend to show more opportunistic and non-cooperative behaviours are sanctioned. Resultantly, in denser networks, there is a higher exchange of instrumental and expressive exchange. Social solidarity and higher level of voluntary social behaviour are some of the positive outcomes of dense social networks (Moody \& White, 2003). In consideration to the above arguments, following is the second hypothesis tested in this research paper:

\section{H2: Network density has a positive association with POS.}

The quality of a social network can be described as the accessibility and availability of high-performing members in the network with which multiplex relationship and exchanges can be formed (Arkar, Sari, \& Fidaner, 2004). The high-performing members of a network engages in helpful citizenship behaviour, propose helpful 
changes, help others, and pursue developmental opportunities and thus they are more likely to provide expressive and instrumental exchange to the employee in order to improve their productivity and performance (Ladd \& Henry, 2000). High-performing members in a social network also tends to improve the overall environment and working conditions in a workplace. Resultantly, it can be inferred that having high-performing members in a network increase the quality ( $\mathrm{Ng} \&$ Sorensen, 2008). Wu and $\mathrm{Hu}$ (2009) have proposed that higher network quality can results in improved POS. Thus, the third hypothesis being tested by this research paper is:

H3: Network quality has a positive association with POS.

This research paper has considered three characteristics to study social network: size, density, and quality and to find their impact on POS. The direct relationship of social network with POS can be attributed largely with the organisational support theory. This theory postulates that the agents of an organisation have a major role to play in understanding the perception of employees regarding the support they receive from in the workplace (Eisenberger et al., 2010). Employees do not consider the organization as a separate or a monolithic entity, on contrary, they consider an organization to comprise of different individuals, behaviors, policies, and actions. Hence, based on the above inference, this research also assess the role of all the network characteristics collectively on the POS. Based on this, following is the last hypothesis which is being tested by this research paper:

H5: Network size, network density, and network quality has a positive association with POS

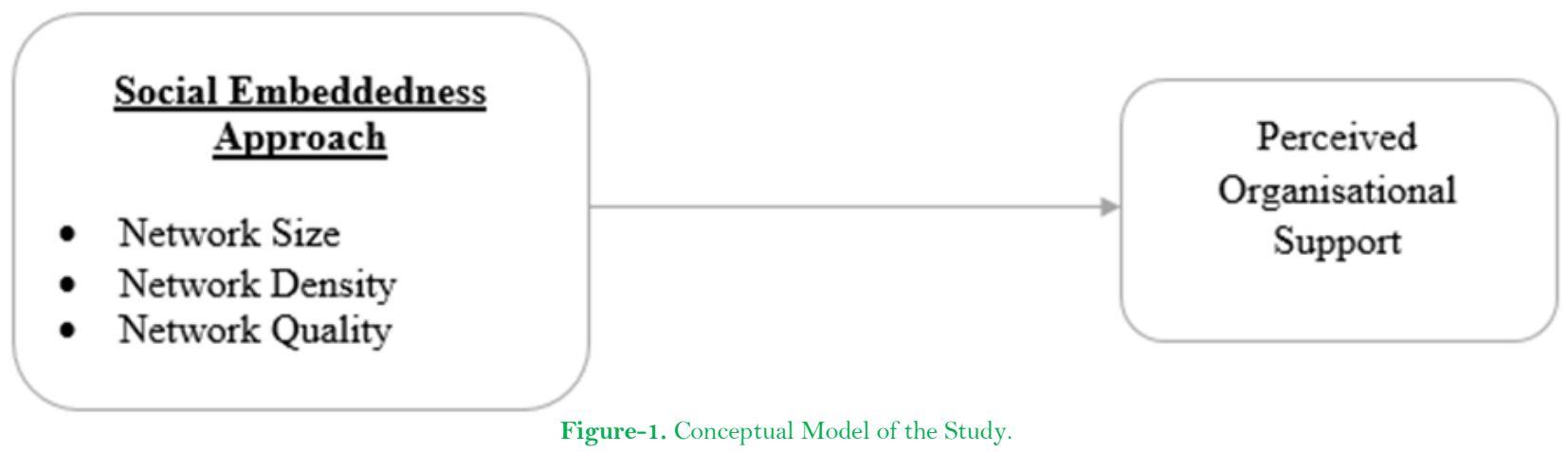

\section{RESEARCH METHODOLOGY}

\subsection{Research Design and Data Collection Process}

The paper uses primary research data collected using close-ended survey questionnaire. The scale is taken to be 5-point ranging from strongly agree to strongly disagree. In addition, the data has been coded to numeric form indicating that this research is quantitative.

\subsection{Sampling Technique and Sample Size}

The sample of the study is based on the employees working in Vietnamn manufacturing sector. The technique to draw the sample is non-probability where purposive sampling has been used. The sample size of the study is 400 employees.

\subsection{Data Analysis Technique}

The data has been analysed using SEM approach which includes path analysis and Confirmatory Factor Analysis (CFA). It specific technique is PLS-SEM whereas, the analysis has been conducted on SmartPLS. 


\section{RESULTS}

\subsection{Confirmatory Factor Analysis (CFA)}

In light of the research methods and techniques that are used in this research paper and that are specified in previous section of methodology, confirmatory factor analysis is used for determining the Alpha Value, reliability and the overall validity of the study. These variables show the extent to which they were significant for the model. Before reaching to the final conclusion whether relationship exists between independent and dependent variables, it is necessary to shed light on whether the variables used are statistically significant or not. Yusoff (2011) stated that in order to prove the statistical viability of variables, it is necessary to note that 0.6 and above values of factor loadings indicate statistical relation. The Table 1 below shows results for confirmatory factor analysis that describes different values of Cronbach Alpha, composite reliability and average variance extracted of each variable. The independent variables in this study are: network size, network density and network quality whereas, dependent variable was perceived organisational support.

Table-1. Confirmatory factor analysis.

\begin{tabular}{|c|c|c|c|c|}
\hline & Factor Loadings & Cronbach's Alpha & Composite Reliability & $\begin{array}{l}\text { Average Variance } \\
\text { Extracted (AVE) }\end{array}$ \\
\hline ND1 & 0890 & 0.887 & 0.930 & 0.816 \\
\hline $\mathrm{ND} 2$ & 0.921 & & & \\
\hline ND3 & 0.898 & & & \\
\hline NQ1 & 0.916 & & & \\
\hline $\mathrm{NQ}^{2}$ & 0.933 & 0.898 & 0.936 & 0.830 \\
\hline NQ3 & 0.884 & & & \\
\hline NS1 & 0.927 & & & \\
\hline $\mathrm{NS} 2$ & 0.866 & & & \\
\hline NS3 & 0.846 & 0.865 & 0.912 & 0.775 \\
\hline POS1 & 0.892 & & & \\
\hline $\mathrm{POS} 2$ & 0.915 & & & \\
\hline POS3 & 0.905 & & & \\
\hline POS4 & 0.830 & 0.908 & 0.936 & 0.785 \\
\hline
\end{tabular}

The table above shows confirmatory factor analysis results based on factor loading values, reliability and Alpha value. Based on the results shown above, the variables and their sub-variables have factor loading value greater than 0.60 which is the generally standard accepted value. This indicates that all the variables are highly suitable for determining the association and relationship between the independent and dependent variables. The next measure for assessing the reliability of the overall model is Alpha value. Gliem and Gliem (2003) stated that Cronbach Alpha value is used to find the internal consistency of the instruments or the scale used in the survey questionnaire. The existing studies have revealed that optimum value of Cronbach Alpha should be higher than 0.70 in order to validate it as statistically reliable for the study. The values of Cronbach Alpha shown above are above 0.70 which indicates that the instrument is highly reliable statistically.

The next measure for analysis shown in the Table 1 above is AVE (average variance extracted) which indicates variance of the variables used which are shown against variance that has occurred due to inaccuracy of measurement. According to the study conducted by Alarcón, Sánchez, and De Olavide (2015) it was found that the standard benchmark value of AVE (average variance extracted) is mostly 0.5 or more than that. As the table above clearly indicates that the values are under the standard value of AVE so, shows the overall reliability hence, including all the measures, the model can be used for further testing. The below Figure 2 shows the overall factor loadings of the model used in current research paper. 


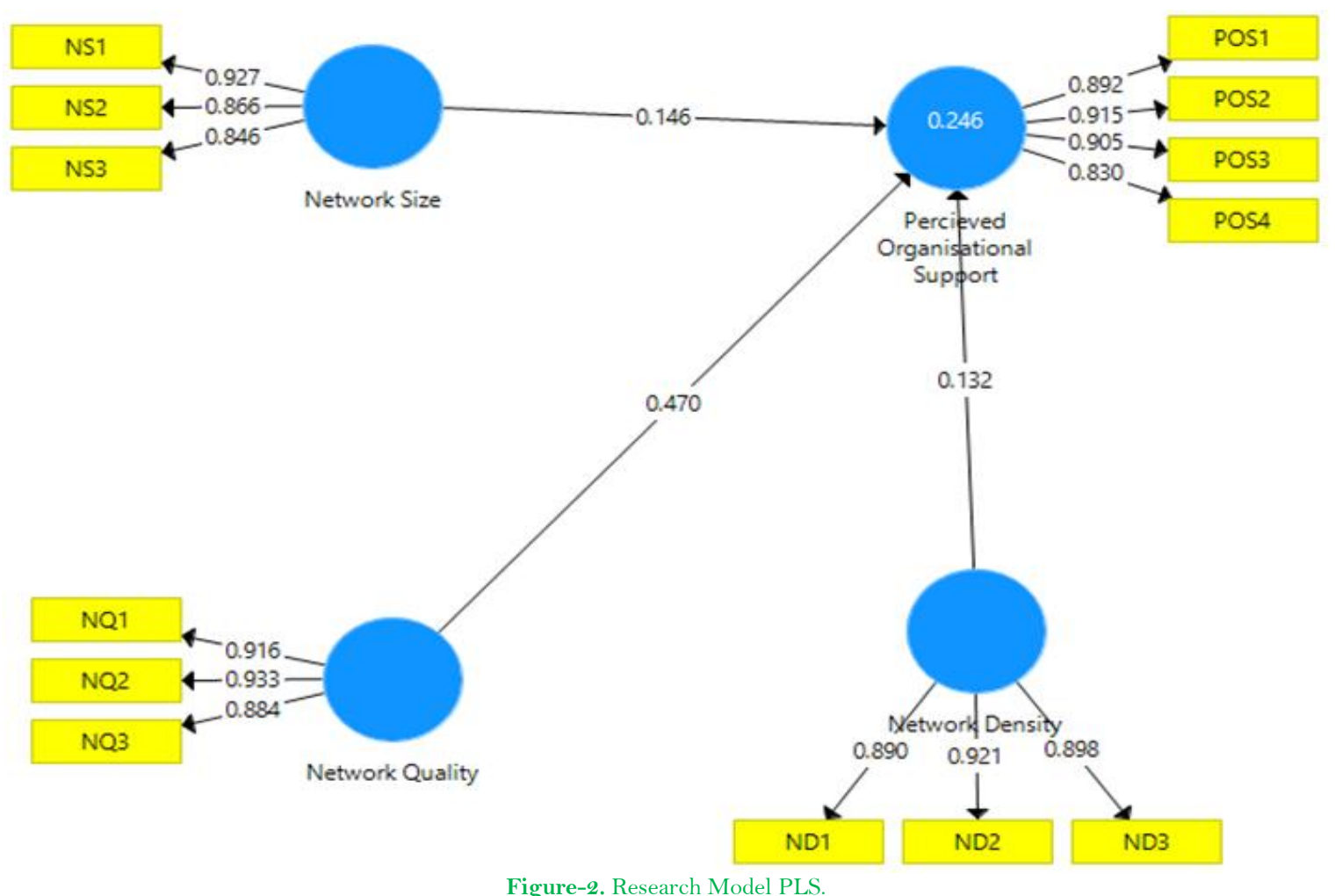

\subsection{Discriminant Validity}

Discriminant validity basically is defined as measure that shows whether the variables that should not be related to each other are similar or not on the basis of values obtained. The Table 2 shows whether the variables are related to each other not.

Table-2. Discriminant Validity.

\begin{tabular}{lcccc}
\hline & $\begin{array}{c}\text { Network } \\
\text { Density }\end{array}$ & $\begin{array}{c}\text { Network } \\
\text { Quality }\end{array}$ & $\begin{array}{c}\text { Network } \\
\text { Size }\end{array}$ & $\begin{array}{c}\text { Perceived Organizational } \\
\text { Support }\end{array}$ \\
\hline Network Density & & & & \\
Network Quality & 0.753 & & \\
Network Size & 0.702 & 0.591 & 0.186 \\
$\begin{array}{l}\text { Perceived Organizational } \\
\text { Support }\end{array}$ & 0.394 & 0.531 & \\
\hline
\end{tabular}

For the current research paper taken into consideration for further analysis, HTMT (Heterotrait-Monotrait Ratio) was used for determining the discriminant validity.

To ensure that the variables used in this research paper are not linked or related with each other, it is necessary to note that HTMT ratio should be 0.90 or less than it.

If the values of the variables are above 0.90 then it indicates that the variables are related with each other. As shown in table 2 of discriminant validity, the values are less than 0.90 which sheds light on the fact that was established initially that variables which should not be related with each other are statistically not related. This increases the accuracy of the data and the validity as well.

\subsection{Basic Model}

The following research paper is aimed at determining the role of social embeddedness approach in perceived organizational support. Therefore, the independent variables in this study are: network size, network density and 
network quality whereas, dependent variable was perceived organisational support. The Table 3 below shows the basic model values which consists of R-square and adjusted R-square value of model used for this paper.

Table-3. Basic Model.

\begin{tabular}{|c|c|c|}
\hline & R Square & R Square Adjusted \\
\hline Perceived Organizational Support & 0.246 & 0.240 \\
\hline
\end{tabular}

As the Table 3 above shows R-square and adjusted R-square values, it is evident that through these indicators, the variance of the predicting factors can be determined and adjustments are made once the variance of predicting factors is obtained.

As it is evident that the R-square value is 0.246 and adjusted R-square value us 0.240 thus, show that network density, network quality and network size can explain $24.6 \%$ changes caused in perceived organizational support. Once the adjustments are made due to any inaccuracies, $24 \%$ was obtained which means that network density, network quality and network size can explain $24 \%$ changes caused in perceived organizational support.

\begin{tabular}{lllccc}
\hline \multicolumn{7}{c}{ Table-4. Coefficients table. } \\
& & & $\begin{array}{c}\text { Original Sample } \\
(\mathbf{O})\end{array}$ & $\begin{array}{c}\text { T Statistics } \\
(\mid \mathbf{O} / \text { STDEV } \mid)\end{array}$ & $\begin{array}{c}\text { P } \\
\text { Values }\end{array}$ \\
\hline $\begin{array}{l}\text { Network Density } \\
\text { Organizational Support }\end{array}$ & & Perceived & 0.132 & 1.775 & 0.076 \\
$\begin{array}{l}\text { Network Quality } \\
\begin{array}{l}\text { Organizational Support } \\
\text { Network Size } \\
\text { Organizational Support }\end{array}\end{array}$ & Perceived & 0.471 & 7.093 & 0.000 \\
\hline
\end{tabular}

The Table 4 above shows the coefficients results of this model. The first independent variable of this model was network density which does not have a significant impact on perceived organizational support because the $\mathrm{P}$ value shown in the table 4 above is 0.076 which is greater than 0.05 hence, cannot be statistically stated as significant. Similarly, the second independent variable of this model was network quality which has a significant impact on perceived organizational support because the $\mathrm{P}$ value shown in the Table 4 above is 0.000 which is less than 0.05 indicating a strong statistical impact on perceived organizational support. The third and last independent variable of this model is network size which has a significant impact on perceived organizational support because the $\mathrm{P}$ value shown in the Table 4 is 0.013 which is less than 0.05 indicating a strong statistical impact on perceived organizational support.

Thus, overall, it can be stated that network density does not have statistically significant impact on perceived organizational support but other two predicting factors that are network quality and network size has significant impact on perceived organizational support because of the values indicated by P-values. The Figure 3 shows the research model, their relationship and their association with each other along with their respective values.

\subsection{Summary of Hypotheses}

In order to conclude the results obtained through testing of variables, the Table 5 shows the results of hypothesis assessment. The assessment table shows the significance values and whether the hypothesis has been accepted or rejected is also indicated here. Thus, results are inTable 5.

The Table 5 indicates that network density does not have a statistically significant relationship with perceived organisational support hence, it is rejected because the P-value is 0.076 which is greater than 0.05. On the other hand, network quality has significant relationship with perceived organisational support because the $\mathrm{P}$-value is 
0.000 which is less than 0.05. And lastly, network size has significant relationship with perceived organisational support because the P-value is 0.013 which is less than 0.05 this, out of the three independent variables tested with perceived organisational support; only 2 are found to have statistically strong relationship and hence, are accepted.

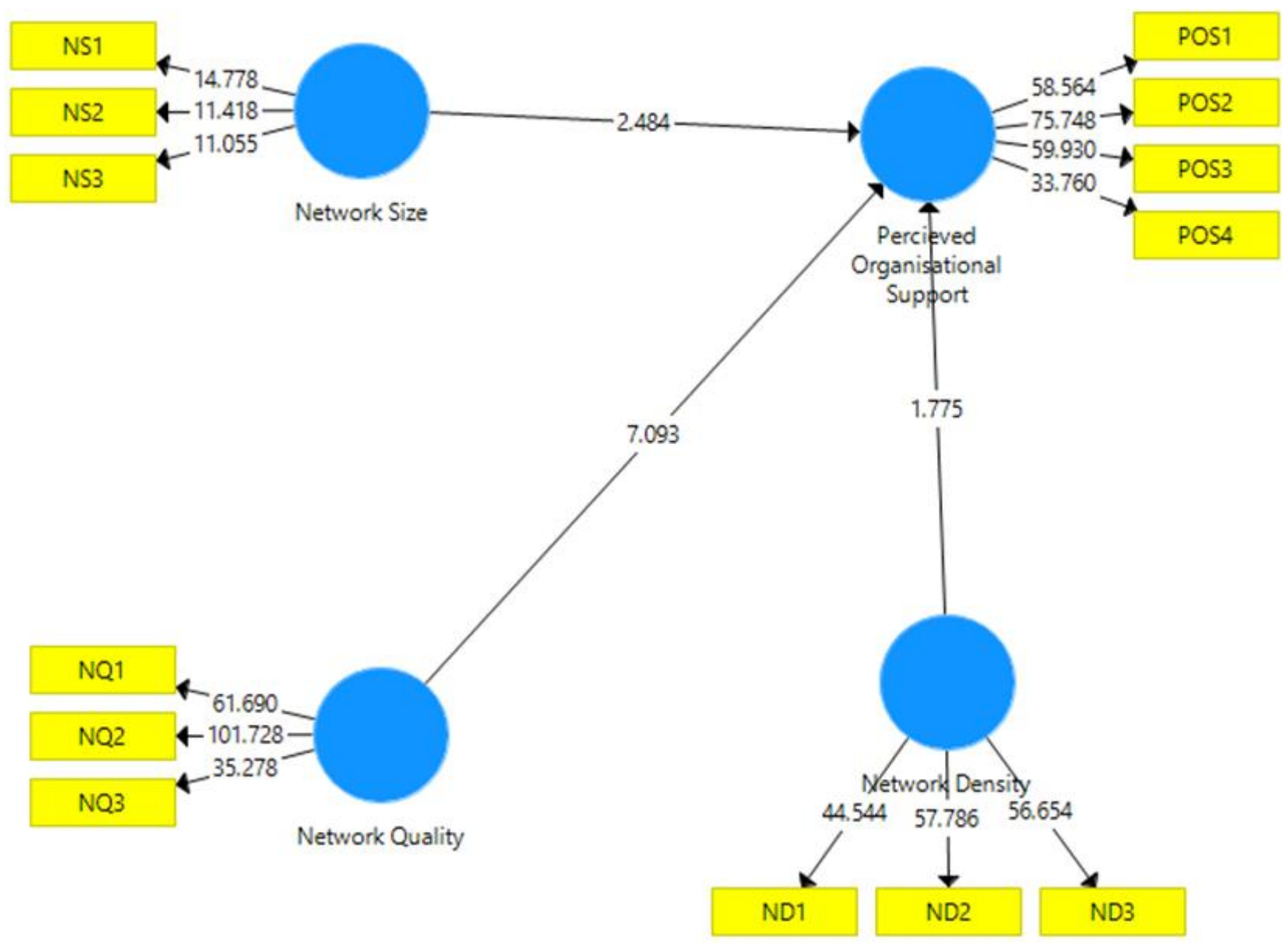

Figure-3. Research Model BTS.

Table-5. Hypothesis assessment table.

\begin{tabular}{clcc}
\hline S. No. & Hypothesis & Sig Value & Results \\
\hline H1 & $\begin{array}{l}\text { Network density has a significant impact on Perceived } \\
\text { Organisational support }\end{array}$ & 0.076 & Rejected \\
H2 & $\begin{array}{l}\text { Network quality has a significant impact on Perceived } \\
\text { organisational support }\end{array}$ & 0.000 & Accepted \\
H3 & $\begin{array}{l}\text { Network size has a significant impact on Perceived } \\
\text { Organisational support }\end{array}$ & 0.013 & Accepted \\
\hline
\end{tabular}

\section{CONCLUSION AND LIMITATIONS}

The following research paper can be concluded by stating that almost every employee who enter a new organisation feel perplexed and stressed. Some organisations do help their employees in feeling relaxed and associate them with the organisational culture whereas, some hardly make any effort which results in employees leaving the organisation too early. Successful attempts of socialization results in better job performance, commitment and retention. Socialization plays a key role in influencing retention of new employees because during the initial year, the turnover chances are high and can be prevented if the employees are made to feel comfortable in the "alien environment and culture". The following research paper aimed to determine determining the role of 
social embeddedness approach in perceived organizational support therefore, the three independent variables selected were network density, network quality and network size whereas the dependent variable was perceived organisational support. Based on these variables, the researcher had conducted a quantitative based study and included different tests results obtained through PLS.

The purpose of conducting this study was the fact that there is limited research available regarding Vietnam with respect to this topic and the researcher intended to explore how social embeddedness plays a vital role in increasing perceived organisational support. The research gap identified became the basis for conducting this study further. In many studies, the relation between overall social embeddedness and perceived organisational support has been explored but none of the studies has shed light on the sub-factors that were taken to find the association or the relationship. This research paper contributes significantly for the managers, head of departments and human resource management who should consider all these factors in order to retain their talented and skilled employees. Furthermore, this study will also be beneficial for those organisations where turnover is rate is high and HR is not able to manage their employees due to diversified cultural environment. Thus, quantitative research design was opted along with primary data collection method to explore and investigate the role of social embeddedness approach in perceived organizational support. The research objectives of the study were to study the theoretical significance and concept of social embeddedness and perceived organizational support, to study the factors of social embeddedness that may influence perceived organizational support and finally, to find the impact of sub-factors of social embeddedness on perceived organizational support. Hence, these objectives were taken into close consideration to achieve the desired results of the study.

The hypothesis was developed to validate whether they have been accepted or rejected. The postulated hypothesis was: the first hypothesis was Network density has a significant impact on Perceived Organisational support, the second hypothesis was Network quality has a significant impact on Perceived Organisational support and finally, the last hypothesis was Network size has a significant impact on Perceived Organisational support. The quantitative study revealed that apart from network density, both network quality and network size has significant impact on Perceived Organisational support.

However, despite of the fact that the study was comprehensive and the data was collected through the survey questionnaire still, there are some limitations of this study which needs to be addressed for the future researchers. This research paper had adopted quantitative method of research design along with primary data whereas, in order to make the study more authentic and reliable, interviews could also be conducted with the HR managers and the senior managers of departments in order to obtain their opinion regarding how skilled and talented employees can be retained through different strategies of social embeddedness. The following study had only evaluated on the basis of the quantitative results whereas, qualitative results could have enhanced the paper and made room for further study in similar domain. Furthermore, the interviews could have been analysed through thematic analysis by designing themes.

The second limitation of this study was the sample size. In existing research method books and studies, it states that the sample size should be large enough in order to make the study more reliable, authentic and valid. Though the following study had used sample size of 400 employees $(\mathrm{N}=400)$ still, it could have been improved and increased to 1000 or 1500 employees. The sample size represents the population taken into consideration and better representation if it helps in making the study more reliable. Hence, if the researcher overcomes these limitations in future then, improvised results could provide more insights. 


\section{REFERENCES}

Akgunduz, Y., \& Sanli, S. C. (2017). The effect of employee advocacy and perceived organizational support on job embeddedness and turnover intention in hotels. Journal of Hospitality and Tourism Management, 31, 118-125. Available at: https://doi.org/10.1016/j.jhtm.2016.12.002.

Alarcón, D., Sánchez, J. A., \& De Olavide, U. (2015). Assessing convergent and discriminant validity in the ADHD-R IV rating scale: User-written commands for Average Variance Extracted (AVE), Composite Reliability (CR), and HeterotraitMonotrait ratio of correlations (HTMT). In Spanish STATA Meeting (Vol. 39): Universidad Pablo de Olavide.

Allen, D. G., \& Shanock, L. R. (2012). Perceived organizational support and embeddedness as key mechanisms connecting socialization tactics to commitment and turnover among new employees. Journal of Organizational Behavior, 34(3), 350369. Available at: $10.1002 /$ job. 1805 .

Allen., D. G., Shore, L. M., \& Griffeth, R. W. (2003). The role of perceived organizational support and supportive human resource practices in the turnover process. Journal of Management, 29(1), 99-118.

Arkar, H., Sari, O., \& Fidaner, H. (2004). Relationships between quality of life, Perceived social support, Social Network, And Loneliness in a Turkish Sample. In New Symposium: journal for psychiatry, neurology and behavioral sciences. Cerrahpasa Medical Faculty Psychiatry Clinic Foundation, 3-7.

Buskens, V., \& Raub, W. (2002). Embedded trust: Control and learning. Advances in Group Processes, 19, 167-202. Available at: https://doi.org/10.1016/s0882-6145(02)19007-2.

Chen, Y.-P., \& Shaffer, M. A. (2017). The influences of perceived organizational support and motivation on self-initiated expatriates' organizational and community embeddedness. Journal of World Business, 52(2), 197-208. Available at: https://doi.org/10.1016/j.jwb.2016.12.001.

Duffy, M. K., Ganster, D. C., \& Pagon, M. (2002). Social undermining in the workplace. Academy of management Journal, 45(2), 331-351.

Eisenberger, R., Karagonlar, G., Stinglhamber, F., Neves, P., Becker, T. E., Gonzalez-Morales, M. G., \& Steiger-Mueller, M. (2010). Leader-member exchange and affective organizational commitment: The contribution of supervisor's organizational embodiment. Journal of Applied Psychology, 95(6), 1085-1103. Available at: https://doi.org/10.1037/a0020858.

Fan, Y., Xia, M., Zhang, Y., \& Chen, Y. (2019). The influence of social embeddedness on organizational legitimacy and the sustainability of the globalization of the sharing economic platform: Evidence from Uber China. Resources, Conservation and Recycling, 151, 104490. Available at: https://doi.org/10.1016/j.resconrec.2019.104490.

Gliem, J. A., \& Gliem, R. R. (2003). Calculating, interpreting, and reporting Cronbach's alpha reliability coefficient for Likert-type scales. Paper presented at the Midwest Research-to-Practice Conference in Adult, Continuing, and Community Education.

Hayton, J. C., Carnabuci, G., \& Eisenberger, R. (2011). With a little help from my colleagues: A social embeddedness approach to perceived organizational support. Journal of Organizational Behavior, 33(2), 235-249. Available at: 10.1002/job.755.

Kanamaru, T. (2015). Beyond the social embeddedness of economic activity: The quality-orientedness in coffee production of Timor-Leste and its implication for legal pluralism. The Journal of Legal Pluralism and Unofficial Lare, 47(2), 267-290.

Ladd, D., \& Henry, R. A. (2000). Helping Coworkers and helping the organization: The role of support perceptions, exchange ideology, and conscientiousness 1. Journal of Applied Social Psychology, 30(10), 2028-2049. Available at: https://doi.org/10.1111/j.1559-1816.2000.tb02422.x.

Lin, N. (2017). Building a network theory of social capital. Social Capital, 3-28. Available at: https://doi.org/10.4324/9781315129457-1.

Mehra, A., Kilduff, M., \& Brass, D. J. (2001). The social networks of high and low self-monitors: Implications for workplace performance. Administrative Science Quarterly, 46(1), 12 1-146. Available at: https://doi.org/10.2307/2667127. 
Moody, J., \& White, D. R. (2003). Structural cohesion and embeddedness: A hierarchical concept of social groups. American Sociological Review, 68(1), 103-127. Available at: https://doi.org/10.2307/3088904.

Ng, T. W., \& Sorensen, K. L. (2008). Toward a further understanding of the relationships between perceptions of support and work attitudes: A meta-analysis. Group \& Organization Management, 33(3), 243-268. Available at: https://doi.org/10.1177/1059601107313307.

Podolny, J. M., \& Baron, J. N. (1997). Resources and relationships: Social networks and mobility in the workplace. American Sociological Review, 62(5), 673-693.

Pollack, J. M., Rutherford, M. W., Seers, A., Coy, A. E., \& Hanson, S. (2016). Exploring entrepreneurs' social network ties: Quantity versus quality. Journal of Business Venturing Insights, 6, 28-35. Available at: https://doi.org/10.1016/j.jbvi.2016.09.001.

Raub, W., \& Weesie, J. (1990). Reputation and efficiency in social interactions: An example of network effects. American Journal of Sociology, 96(3), 626-654. Available at: https://doi.org/10.1086/229574.

Tabak, F., \& Hendy, N. T. (2016). Work engagement: Trust as a mediator of the impact of organizational job embeddedness and perceived organizational support. Organization Management Journal, 13(1), 21-31. Available at: https://doi.org/10.1080/15416518.2015.1116968.

Trading Economics. (2020). Manufacturing industry of Vietnam. Retrieved from: https://tradingeconomics.com/vietnam/manufacturing-production.

Wu, T. Y., \& Hu, C. (2009). Abusive supervision and employee emotional exhaustion: Dispositional antecedents and boundaries. Group E Organization Management, 34(2), 143-169.

Yusoff, M. S. B. (2011). Psychometric properties of the learning approach inventory: A confirmatory factor analysis. Education in Medicine Journal, 3(2), e24-e31. Available at: https://doi.org/10.5959/eimj.3.2.2011.or3. 